\title{
Nicotinamide sensitizes human breast cancer cells to the cytotoxic effects of radiation and cisplatin
}

\author{
G. DOMÍNGUEZ-GÓMEZ ${ }^{1,2}$, J. DÍAZ-CHÁVEZ ${ }^{2}$, A. CHÁVEZ-BLANCO ${ }^{2}$, A. GONZALEZ-FIERRO ${ }^{2}$, \\ J.E. JIMÉNEZ-SALAZAR ${ }^{1}$, P. DAMIÁN-MATSUMURA ${ }^{3}$, L.E. GÓMEZ-QUIROZ ${ }^{4}$ and A. DUEÑAS-GONZÁLEZ ${ }^{2,5}$ \\ ${ }^{1}$ Postgraduate Program on Experimental Biology, Autonomous Metropolitan University at Iztapalapa, Mexico; \\ ${ }^{2}$ Unit of Biomedical Research in Cancer, Biomedical Research Institute, National Autonomous University of Mexico/ \\ National Cancer Institute, Mexico; ${ }^{3}$ Department of Reproductive Biology, Autonomous Metropolitan \\ University at Iztapalapa, Mexico; ${ }^{4}$ Department of Health Sciences, Autonomous Metropolitan \\ University at Iztapalapa, Mexico; ${ }^{5}$ Tumor Study Group A.C. Mexico
}

Received October 1, 2014; Accepted November 18, 2014

DOI: $10.3892 / o r .2014 .3661$

\begin{abstract}
Poly(ADP-ribose) polymerase (PARP) inhibitors enhance the effect of DNA alkylating agents on $B R C A 1$ - and $B R C A 2$-deficient cell lines. The aim of this study was to analyze the effect of the PARP inhibitor nicotinamide (NAM) on breast cancer cells with different $B R C A 1$ expression or function, such as BRCA1-deficient MDA-MB-436 cells, low expression BRCA1 MCF-7 cells, and the BRCA1 wild-type MDA-MB-231 cells, to demonstrate its effects as a chemoor radiosensitizing agent. PARP activity was analyzed in MDA-MB-436, MCF-7 and MDA-MB-231 breast cancer cells subjected or not to NAM. Inhibition of PARP by NAM in the presence of DNA damage was examined by Alexa Fluor 488 immunofluorescence. Crystal violet assays were used to test growth inhibition and the chemo- and radiosensitization effects of NAM were investigated using clonogenic assays. Significant differences among data sets were determined using two-tailed ANOVA and Bonferroni tests. We demonstrated that NAM reduces PARP activity in vitro, and in cells subjected or not to DNA damage, it also reduces the viability of breast cancer cell lines and synergyzes the cytotoxicity of cisplatin in MDA-MB-436 and MCF-7 cells. Downregulation of PARP1 with siRNA led to modest growth inhibition, which was further increased by cisplatin. Nicotinamide also induced radiosensitization in MDA-MB436 and MDA-MB-231 cells. In conclusion, NAM may be used as a chemo- or radiosensitizing agent regardless of the BRCA1 status in breast cancer.
\end{abstract}

Correspondence to: Dr A. Dueñas-González, San Fernando 1, Tlalpan 14080, Edificio la Herradura, México City, México

E-mail: alfonso_duenasg@yahoo.com

Key words: niconamide, breast cancer, BRCA1, poly(ADP-ribose) polymerase, cisplatin

\section{Introduction}

Poly(ADP-ribose) polymerase (PARP) enzyme inhibitors are emerging as a valuable new drug class in the treatment of cancer. PARP-1 is the founding member of a family of 18 PARP members that have been identified thus far. PARP-1 functions as a key molecule in the repair of DNA singlestrand breaks (SSBs) via the base excision DNA repair (BER) pathway (1). Inhibitors of PARP-1 have been shown to enhance the cytotoxic effects of ionizing radiation and DNA-damaging chemotherapeutic agents in vitro and in vivo $(2,3)$. Early preclinical and clinical trial data suggest that PARP inhibitors may be used as chemo/radiotherapy sensitizers and as single agents to selectively kill cancers defective in DNA repair, specifically cancers with germ-line mutations in breast cancer-associated $B R C A 1$ and $B R C A 2$ genes, a strategy known as 'synthetic lethality' (4-7). There are currently at least eight PARP inhibitors being developed (8), however, the development of new drugs is extremely costly and there is a gap between the resources invested in drug development and their translatability into longer survival for cancer patients.

Repurposing existing drugs is another strategy for drug development in which safety pharmacology studies have been already done, which reduces the time and cost of approving the compounds for clinical use $(9,10)$. Nicotinamide (NAM; pyridine-3-carboxylic acid) is a water-soluble amide active form of vitamin B3 or niacin. NAM and niacin are precursors for the synthesis of nicotinamide adenine dinucleotide $\mathrm{NAD}^{+}$and the phosphorylated derivative $\mathrm{NADH}^{+}(11)$. This drug has been used for the treatment of pellagra, diabetes mellitus, acne and schizophrenia and has been shown to have low toxicity even at high doses (12). NAM was identified as the first inhibitor of PARP, while the majority of PARP inhibitors contain the NAM pharmacophore (13). Preclinical studies have shown that NAM may exert antitumor effects and reverse chemotherapy resistance in some models (14). In addition, this drug is currently used as a component of accelerated radiotherapy with carbogen and nicotinamide (ARCON), a therapeutic strategy used in non-small cell lung cancer, head 
and neck and bladder cancer (15-18). In the present study, the results showed that NAM increased the cytotoxic effects of cisplatin and radiation on breast cancer cells.

\section{Materials and methods}

Cell lines. The MDA-MB-436, MDA-MB-231 and MCF7 human breast cancer cell lines were obtained from the American Type Culture Collection (ATCC, Rockville, MD, USA). MDA-MB-436 cells harbor 5396+1G > A (spliced donor site of exon 20), a BRCA1 mutation. MCF-7 and MDA-MB-231 cells express wild-type BRCA1 while MDA-MB-231 cells are hemizygous for $B R C A 1$, with loss of one allele and the remaining non-mutated allele containing two non-pathogenic single-nucleotide polymorphisms. The cell lines were cultured in DMEM/F-12 medium, $10 \%$ fetal bovine serum, penicillin $(100 \mathrm{U} / \mathrm{ml})$, and streptomycin $(1.0 \mathrm{mg} / \mathrm{ml})$ at $37^{\circ} \mathrm{C}$ in a humidified atmosphere of $5 \% \mathrm{CO}_{2}$ and $95 \%$ air.

PARP activity assay. PARP activity in vitro was assayed using the Trevigen Universal Chemiluminescent PARP assay kit (Trevigen Inc., Gaithersburg, MD, USA) according to the manufacturer's instructions. Recombinant PARP was incubated for $1 \mathrm{~h}$ with different NAM doses $(0.05,0.1,0.2,0.5,0.75$ and $1 \mathrm{mM})$ in the presence of activated DNA. Chemiluminescent detection was performed as per the manufacturer's instructions. To assay endogenous PARP activity, cells were grown in a $25-\mathrm{cm}^{2}$ cell culture flask in medium alone or with NAM for $72 \mathrm{~h}$. The cells were washed once with ice-cold PBS, lysed in $50 \mu 1$ of PARP buffer containing $0.5 \mathrm{~mol} / 1 \mathrm{NaCl}, 1 \%$ (v/v) NP-40, and protease inhibitors (Sigma-Aldrich, St. Louis, MO, USA) on ice for $30 \mathrm{~min}$ with occasional vortexing. The lysates were clarified by centrifugation at $14,000 \mathrm{rpm}$, at $4^{\circ} \mathrm{C}$ for $10 \mathrm{~min}$. The protein concentration of the extracts was determined using the Bradford protein dye reagent (Bio-Rad, Hercules, CA, USA), and PARP activity was assayed using the Trevigen Universal Chemiluminescent PARP assay kit according to the manufacturer's instructions, with modifications. The lysate $(30 \mu \mathrm{g} / \mathrm{well})$ was added in duplicate to wells containing PARP buffer and PARP cocktail, followed by incubation at room temperature for $1 \mathrm{~h}$ with NAM at concentrations of $0.5,0.75$ and $1 \mathrm{mM}$. Activated DNA was added to the standards but was omitted from the extracts. The plate was washed three times with PBS and three times with PBS and $0.1 \%$ Triton X-100, followed by incubation with streptavidin horseradish peroxidase $(1: 1,000$ dilution) in diluent buffer for $1 \mathrm{~h}$. The plate was washed again three times with PBS alone and three times with PBS and $0.1 \%$ Triton X-100. Chemiluminescent detection was performed as per the manufacturer's instructions. The background reading was subtracted from the readings of the samples, and PARP activity was calculated using the standard curve obtained from readings of the standards.

Immunofluorescence. The MCF-7, MDA-MB-436 and MDA-MB-231 cells were grown in chamber slides (SigmaAldrich) at a $70 \%$ of confluence. Immunostaining for poly (ADP-ribose) (PAR) was performed on cells fixed in ice-cold $4 \%$ paraformaldehyde in PBS for $10 \mathrm{~min}$. The cells were fixed $1 \mathrm{~h}$ after treatment with NAM at concentrations of $0.5,1,5$ and $10 \mathrm{mM}$ and exposed to $\mathrm{H}_{2} \mathrm{O}_{2}\left(1 \mathrm{mmol} / 1,10 \mathrm{~min}, 37^{\circ} \mathrm{C}\right)$. Controls were treated with medium alone. The primary antibody used was anti-pADPR (H10, Santa Cruz Biotechnology, Inc., Santa Cruz, CA, USA). Poly ADP-ribosylation immunostaining was developed following NAM treatment. The secondary antibody used was the Alexa Fluor 488-conjugated goat anti-mouse IgG antibody (Molecular Probes, Life Technologies, Carlsbad, CA, USA). Nuclear counterstaining with DAPI was performed after removal of excess secondary antibody. Immunostaining was visualized with a Carl Zeiss confocal multiphotonic laser microscope 780 NLO (Hamburg, Germany).

Cell viability assay. Cell viability was assessed by crystal violet staining. Semi-confluent culture flasks were trypsinized and $2.5 \times 10^{4}$ cells were seeded in 12 -well plates. After $24 \mathrm{~h}$, the cells were exposed to NAM $(5,10,20,40,60,80$ and $100 \mathrm{mM})$ and cisplatin $(20,40,60$ and $80 \mu \mathrm{M})$ at the indicated concentrations. After $72 \mathrm{~h}$, the cells were rinsed with PBS, fixed in $2 \%$ formaldehyde for $5 \mathrm{~min}$ and stained with $1 \%$ crystal violet. Relative cell viability was obtained by scanning with an ELISA plate reader at $540 \mathrm{~nm}$.

Data analysis of drug combination. Synergism or additivity was determined by calculating the combination index (CI) using the equation: $\mathrm{CIx}=(\mathrm{D} 1 / \mathrm{Dx} 1)+(\mathrm{D} 2 / \mathrm{Dx} 2)+\mathrm{a}(\mathrm{D} 1)(\mathrm{D} 2) /$ (Dx1)(Dx2), where CIx is the CI value for $\mathrm{x} \%$ effect, Dx1 and Dx 2 are the doses of agents 1 and 2 required to exert $x \%$ effect alone, and D1 and D2 are the doses of agents 1 and 2 that elicit the same $\mathrm{x} \%$ effect in combination with the other agent, respectively. The factor indicates the type of interaction: $a=0$ for mutually exclusive drugs (similar mechanisms of action), and $\mathrm{a}=1$ for mutually non-exclusive drugs (independent modes of action), with the equation being resolved for $\mathrm{a}=1$. A CI of 1 indicates additivity, a $\mathrm{CI}$ of $<1$ synergism and a $\mathrm{CI}$ of $>1$ antagonism.

siRNA transfection assay. Cells were seeded in 12-well plates Nunc (Thermo Scientific ${ }^{\mathrm{TM}}$ Nunclon, Waltham, MA, USA) at $15 \times 10^{3}$ cells/well into $0.5 \mathrm{ml}$ of Optimem (Applied Biosystems Life Technologies, Carlsbad, CA, USA). After $24 \mathrm{~h}$, the cells were transfected with lipofectamine and PARP1 siRNA (cat no. 4390824; Ambrion, Minneapolis, MN, USA) or RNAiMAX containing siRNA Scramble (cat no. 4390844; Ambrion). Cisplatin was added for $24 \mathrm{~h}$ and the cells were cultured at $37^{\circ} \mathrm{C}$ in humidified atmosphere containing $5 \%$ $\mathrm{CO}_{2}$. After $72 \mathrm{~h}$, the medium was aspirated and the cells were processed for western blotting and cell viability.

Radiation and drug treatment. Ionizing radiation (IR) of cells was performed at room temperature in culture medium, using a Theratron Phoenix (60Co) irradiator (Best Theratronics Ltd., Ottawa, Ontario, Canada) with an average energy of $1.25 \mathrm{MeV}$ in a field of $20 \times 20 \mathrm{~cm}^{2}$, to a distance isocenter of $80 \mathrm{~cm}$. Cell lines were irradiated at a range of 0.5-6 Gy in the presence of different concentrations of NAM (0.5-20 mM). Control cells were treated with medium only.

Clonogenic assay. Exponentially proliferating cells were plated into a $25-\mathrm{cm}^{2}$ cell culture flask and incubated for $48 \mathrm{~h}$ to allow cells to reach their optimum proliferation rate. NAM $(0.5,1,5,10$ and $20 \mathrm{mM})$ was added to the dishes and incu- 
bated for $72 \mathrm{~h}$ and the cells were irradiated. Control cells were not treated. Cells were collected and cultured in drug-free medium in $60 \mathrm{~mm}$ Petri dishes for up to 21 days, depending on the proliferation rate of the individual cell line. Colonies were fixed in methanol and acetic acid (3:1 v/v), stained with crystal violet and counted with a stereoscopic microscopy [Leica Microsystems, (Schweiz) AG, Heerbrugg, Switzerland]. Data are expressed as the percentage of colonies in NAM-treated cultures compared with control cultures. Lethal concentration $50\left(\mathrm{LC}_{50}\right)$ was calculated for each cell line in each independent experiment. Each assay was performed in triplicate for each concentration. Plating efficiencies and the surviving fractions were calculated.

Statistical analysis. Data are expressed as the mean \pm SD values. For statistical analysis the ANOVA and Bonferroni post-tests were used to mediate GraphPad Prism 5. $\mathrm{P}<0.05$ was considered to indicate a statistically significant difference.

\section{Results}

Nicotinamide decreases PARP activity. To examine whether NAM can inhibit PARP activity in vitro, a cell-free PARP activity assay was performed. Recombinant PARP was incubated for $1 \mathrm{~h}$ at different concentrations of NAM $(50,100$, 200, 500, 750, and 1,000 $\mu \mathrm{M})$. A significant dose-dependent decrease of PARP activity, starting at $500 \mu \mathrm{M}$ was observed (Fig. 1A). We also examined whether NAM similarly inhibits PARP cell activity in MDA-MB-436 breast cancer cells deficient in BRCA1. Whole-cell lysates were incubated in the presence of nicotinamide adenine dinucleotide $\mathrm{NAD}^{+}$and a conjugated histone acceptor protein, and in the absence of activated DNA, allowing us to determine already activated PARP. A significant decrease in PARP activity was observed (Fig. 1B).

Nicotinamide reduces poly ADP-ribosylation in the presence of DNA damage. To confirm that NAM inhibits poly-ADPribosylation, we induced DNA damage with $\mathrm{H}_{2} \mathrm{O}_{2}(10 \mathrm{mmol} / \mathrm{l}$ for $10 \mathrm{~min}$ ) leading to poly-ADP ribosylation in the three cell lines after treatment with $0.5,0.75,1,5$ and $10 \mathrm{mM}$ of NAM. We performed a series of immunofluorescent stainings using anti-pADPR. Fig. 2 shows that poly-ADP ribosylation was detected in the nuclei of cells treated with $\mathrm{H}_{2} \mathrm{O}_{2}$. Its effect was reduced as a consequence of NAM treatment in a dose-dependent manner.

Growth inhibition by nicotinamide and cisplatin. To determine whether PARP inhibition with NAM sensitizes cell to cisplatin-induced death, we treated MDA-MB-436, MDA-MB-231 and MCF-7 cell lines with cisplatin $(0-100 \mu \mathrm{M})$ and NAM $(5,10,20,40,60,80$ and $100 \mathrm{mM})$ and determined the $\mathrm{IC}_{50}$ value. Fig. $3 \mathrm{~A}-\mathrm{C}$ shows the $\mathrm{IC}_{50}$ value for NAM in each cell line (20-30 mM). On the other hand, because it has been reported that deficient BRCA1 cells are more sensitive to agents that induce DNA damage, we analyzed the effect of cisplatin in three cell lines to obtain the $\mathrm{IC}_{20}$ value through a dose response curve. The results demonstrated that MDA-MB-436 cells (Fig. 3D-F), deficient of BRCA1 were more sensitive than MDA-MB-231 and MCF-7 cells.
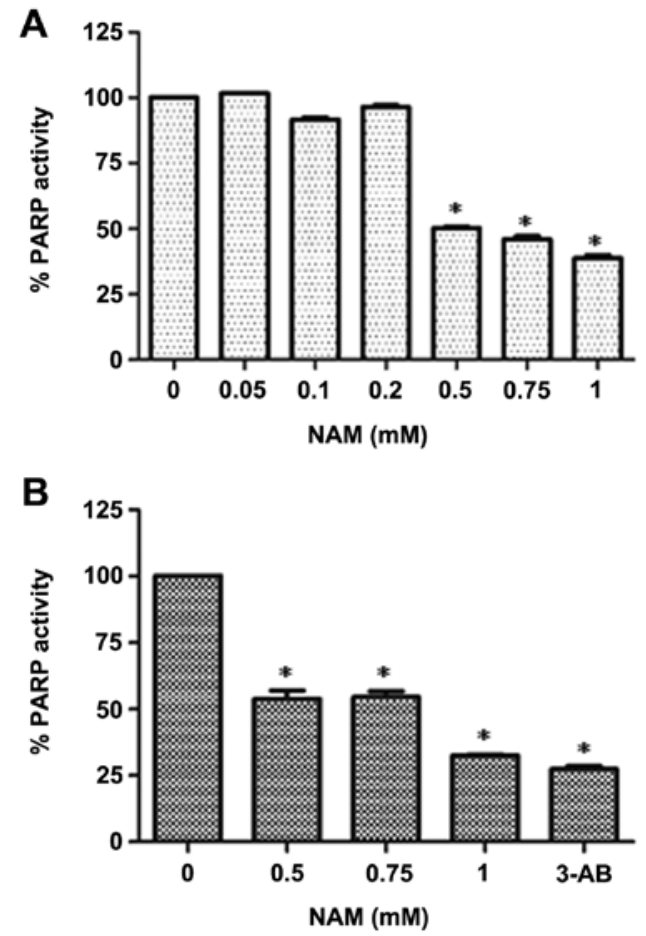

Figure 1. PARP inhibition by nicotinamide. (A) Nicotinamide inhibits in vitro PARP activity at concentrations starting at $0.5 \mathrm{mM}$. (B) Endogenous inhibition of PARP. At $1 \mathrm{mM}$ inhibitory activity is similar to that achieved by the known PARP inhibitor 3-aminobenzamide. The average and SD from at least three experiments are shown. *Statistically significant compared with the control $(\mathrm{p}<0.001)$.

Nicotinamide sensitizes breast cancer cells to cisplatin toxicity. We also analyzed the effect of co-treatment of NAM and cisplatin using a lower dose of cisplatin $\left(\mathrm{IC}_{20}\right)$ and varying doses of $\operatorname{NAM}(5,10,20$ and $40 \mathrm{mM})$. The results demonstrated that a combination of NAM and cisplatin significantly decreased the viability of MDA-MB-436 and MCF-7 cells as compared to NAM alone ( $\mathrm{P}<0.001$, Fig. $4 \mathrm{~A}$ and $\mathrm{C})$, while MDA-MB-231 cells showed no significant differences (Fig. 4B). On the other hand, when comparing the effect of NAM and cisplatin on the viability of breast cancer cells, we observed a significantly higher decrease compared to cisplatin alone $(\mathrm{P}<0.001)$. To verify these results we determined the CI (combination index) using the median-effect method which revealed a clear synergistic interaction between NAM and cisplatin (CI <1) in MDA-MB-436 and MCF-7 cells (Table I), whereas MDA-MB-231 cells failed to show a synergistic interaction.

Growth inhibition by PARPI knockdown is increased by cisplatin. To determine to what extent the downregulation of PARP1 inhibited cell growth, MDA-MB-436 were subjected to siRNA against PARP1. The results showed that at $72 \mathrm{~h}$ there was complete knockdown of mRNA of PARP1 and cell growth was inhibited by $10 \%$. When cisplatin was added this inhibition increased as compared to cisplatin alone or PARP1 inhbition. These differences were statistically significant. No growth effects were observed for scramble siRNA with or without cisplatin (Fig. 5).

Radiosensitivity in breast cancer cells by nicotinamide. The effect of NAM in combination with ionizing radiation (IR) 


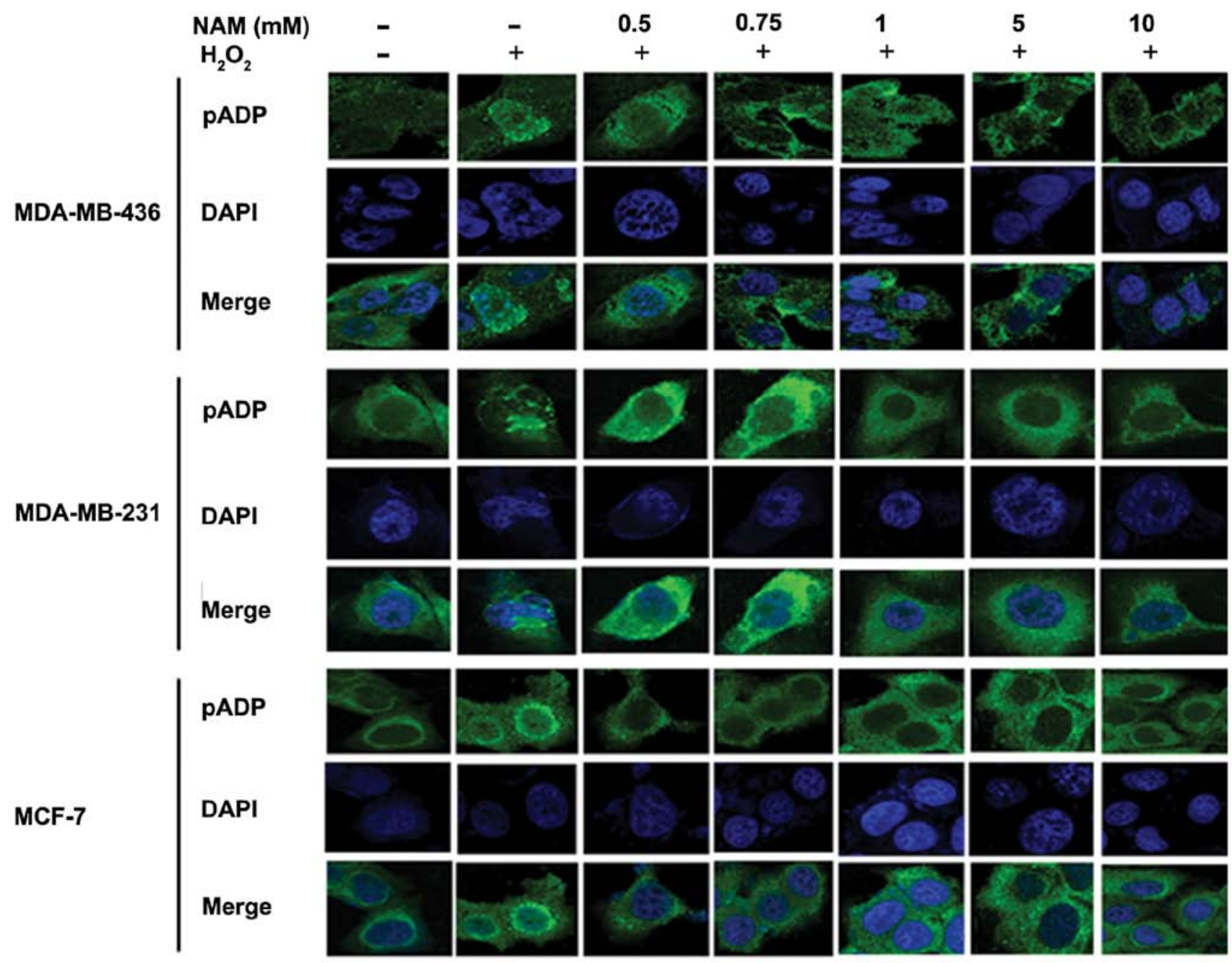

Figure 2. Endogenous PARP inhibition of ADP-ribosylation in cell nuclei. Nicotinamide inhibits the nuclear formation of polymers (ADP-ribosylation, pADP, green) in the presence of DNA damage induced by $\mathrm{H}_{2} \mathrm{O}_{2}$. Nuclei were counterstained with DAPI.

through clonogenic assay was analyzed to determine the colony-forming ability from a cell after inducing DNA damage. Survival curves were performed to determine the median lethal doses (LD50), which were defined as the absorbed dose of ionizing radiation (Gy) required to induce $50 \%$ cell death. The results demonstrated a different sensitivity to IR in cell lines. MDA-MB-436 cells were more sensitive to IR than MDA-MB-231 and MCF-7 cells (data not shown). Subsequently, we analyzed the effect of NAM combined with IR. A significant decrease in cell survival levels in MDA-MB-436 and MDA-MB-231 cells exposed to the combination compared with NAM only was observed $(\mathrm{P}<0.001$, Fig. $6 \mathrm{~A}$ and $\mathrm{B})$, while MCF-7 cells showed no significant differences $(\mathrm{P}<0.001$, Fig. 6C). When comparing the effect of the combination of NAM and IR versus IR only, we observed a significant effect on survival $(\mathrm{P}<0.001$, Fig. 6A and $\mathrm{B})$, while MCF-7 cells showed no significant difference $(\mathrm{P}<0.001$, Fig. $6 \mathrm{C})$.

\section{Discussion}

The results of this study show that NAM inhibits the growth of breast cancer cell lines in a dose-dependent manner. In addition, depletion of PARP1 mRNA reduces cell viability and
NAM increases the cytotoxic effects of cisplatin and induces radiosensitization to various degrees in MDA-MB-436, MDA-MB-231 and MCF-7 breast cancer cell lines.

A number of PARP inhibitors are being developed in the clinic as single agents and/or in combination with other drugs as potential enhancers of DNA-damaging cytotoxic agents, such as alkylating agents or radiation therapy. The chemistry of most of these agents is that of reversible NAD ${ }^{+}$mimetics, although they have different bioavailability and molar equivalence for PARP enzyme inhibition $(1,8)$. Nevertheless, cancer drug development needs alternative approaches for drug identification because of increasing failure rates, high cost, poor safety, limited efficacy, and a lengthy design and testing process of new entities. In this sense, drug repurposing of established non-cancer drugs that have anticancer activity provides an opportunity to rapidly advance therapeutic strategies in clinical trials $(9,10)$.

Despite the long-established activity of NAM as a PARP1 inhibitor this drug has not been extensively evaluated as anticancer agent. However, it has largely been used in the clinic at pharmacological doses over many years with a low incidence of side effects and toxicity for diverse conditions including dermatological, metabolic and psychiatric disorders (19-22). 

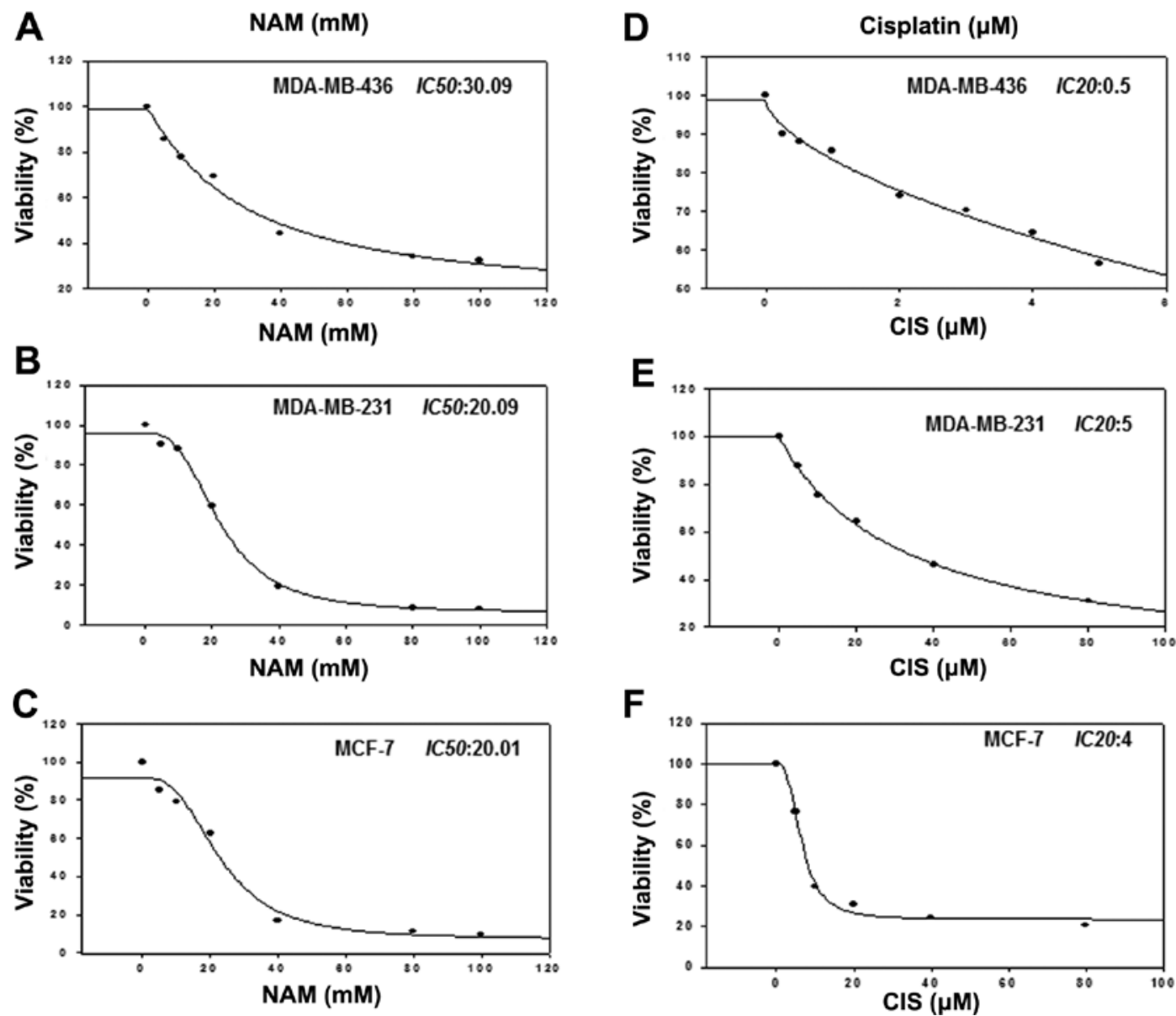

Figure 3. Growth inhibition by nicotinamide and cisplatin. MDA-MB-436, MDA-MB-231 and MCF-7 cell lines were treated with cisplatin (0-100 $\mu$ M) and $\operatorname{NAM}(5,10,20,40,60,80$ and $100 \mathrm{mM})$ to determine their $\mathrm{IC}_{50}$ and $\mathrm{IC}_{20}$ values, respectively. (A-C) $\mathrm{IC}_{50}$ values for NAM were $30.09,20.09$ and $20.01 \mathrm{mM}$. (D-F) The corresponding $\mathrm{IC}_{20}$ for cisplatin was $0.5,5$ and $4 \mu \mathrm{M}$.
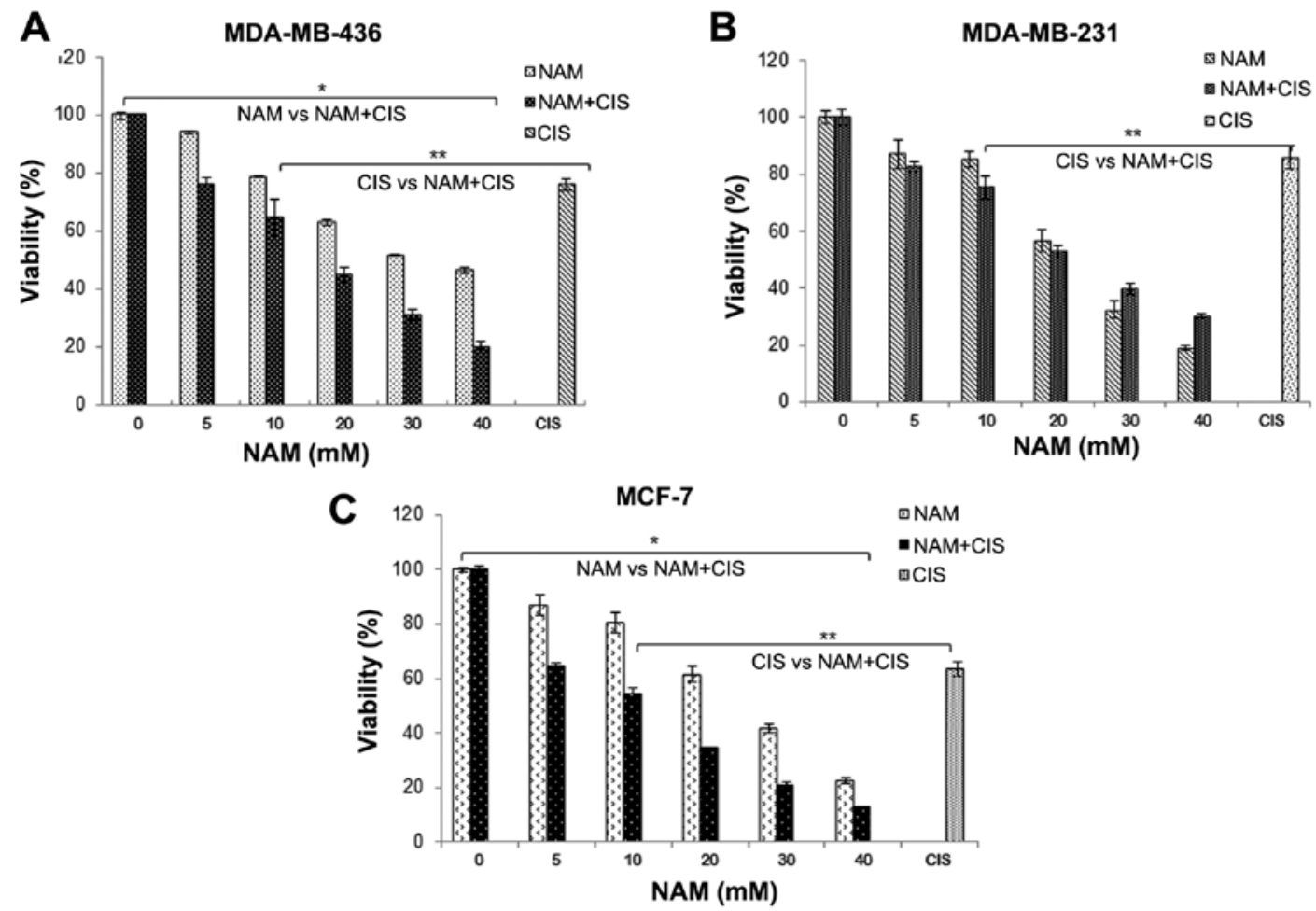

Figure 4. Chemosensitization by nicotinamide. Cells were treated with different doses of NAM for $72 \mathrm{~h}$ and cisplatin by $24 \mathrm{~h}$. Average and SD from at least three experiments are shown. "Statistically significant with respect to NAM vs NAM+CIS ( $<<0.001)$. ${ }^{* *}$ Statistically significant with regard to CIS vs NAM (p<0.001). 
Table I. Combination index of nicotinamide and cisplatin.

\begin{tabular}{|c|c|c|c|c|c|c|c|}
\hline \multirow[t]{2}{*}{ Cell line } & \multicolumn{4}{|c|}{ Doses $(\mathrm{mM})$} & Control growth & \multirow[t]{2}{*}{ Combination index (Cix) } & \multirow[t]{2}{*}{ Interaction } \\
\hline & $\begin{array}{l}\text { Nicotinamide } \\
\text { (D1) }\end{array}$ & $\begin{array}{l}\text { Cisplatin } \\
\text { (D2) }\end{array}$ & $\begin{array}{l}\text { Nicotinamide } \\
\text { (Dx1) }\end{array}$ & $\begin{array}{l}\text { Cisplatin } \\
\text { (Dx2) }\end{array}$ & $(\mathrm{x} \%)$ & & \\
\hline \multirow[t]{5}{*}{ MDA-MB-436 } & 5 & 0.0005 & 11.1 & 0.0018 & 76 & 0.73 & Synergistic \\
\hline & 10 & 0.0005 & 18.65 & 0.0041 & 64 & 0.66 & Synergistic \\
\hline & 20 & 0.0005 & 39.14 & 0.11 & 45 & 0.52 & Synergistic \\
\hline & 30 & 0.0005 & 121 & 0.12 & 31 & 0.25 & Synergistic \\
\hline & 40 & 0.0005 & 122 & 0.13 & 19 & 0.33 & Synergistic \\
\hline \multirow[t]{5}{*}{ MDA-MB-231 } & 5 & 0.005 & 7.33 & 0.0082 & 82 & 1.29 & \\
\hline & 10 & 0.005 & 10.03 & 0.0133 & 75 & 1.37 & \\
\hline & 20 & 0.005 & 20.27 & 0.0345 & 52 & 1.13 & \\
\hline & 30 & 0.005 & 28.35 & 0.0516 & 39 & 1.16 & \\
\hline & 40 & 0.005 & 35.9 & 30.03 & 30 & 1.28 & \\
\hline \multirow[t]{5}{*}{ MCF-7 } & 5 & 0.004 & 14.34 & 0.0055 & 64 & 1.08 & \\
\hline & 10 & 0.004 & 19.73 & 0.0082 & 54 & 0.99 & \\
\hline & 20 & 0.004 & 34.28 & 0.0166 & 34 & 0.82 & Synergistic \\
\hline & 30 & 0.004 & 51 & 0.15 & 20 & 0.62 & Synergistic \\
\hline & 40 & 0.004 & 66 & 0.2 & 12 & 0.63 & Synergistic \\
\hline
\end{tabular}

In cancer, NAM has been used in clinical studies in combination with accelerated radiotherapy with carbogen and nicotinamide (ARCON) for radiosensitation (12,16-18). In the present study, we demonstrate that NAM effectively inhibits PARP activity in vitro, results that are consistent with those of previous reports (13). In addition, we show that NAM inhibits endogenous PARP activity in extracts from BRCA1-deficient MDA-MB-436 cells. PARP is important in DNA repair, and our results showed that NAM inhibits ADP-ribosylation in the presence of DNA damage induced by $\mathrm{H}_{2} \mathrm{O}_{2}$ in a dose-dependent manner in the three breast carcinoma cell lines examined, suggesting that NAM blocks DNA repair through PARP-1 inhibition. This effect is observed in the three breast cancer lines, indicating that its action is independent of the BRCA1 status. We analyzed whether inhibition of PARP induced by NAM or knockdown of PARP1 mRNA may have an effect on cell viability, demonstrating that both experimental conditions reduce cell viability.

It has been reported that PARP inhibition may potentiate the effects of antineoplastic DNA-damaging agents such as temozolomide, cyclophosphamide and platinum in BRCA1-deficient cells (23). Similarly, AZD2281, another PARP inhibitor, in combination with cisplatin synergistically induced cell growth inhibition of breast cancer cells deficient in $B R C A 2$ (24). In agreement with findings of that report, our results demonstrate that the combination of NAM with cisplatin significantly decreased cell viability in the three breast cancer cell lines regardless of the BRCA1 status. Thus, NAM induces synthetic lethality in BRCA1-deficient breast cancer cells as is the case for other PARP inhibitors.

Inhibition of PARP activity reduced the single-strand breaks (SSBs) repair range and increased sensitivity to ionizing radiation and antineoplastic agents. As such, PARP inhibition exerts radiosensitization by facilitating the conversion of an unrepaired SSB to double-strand breaks (DSBs) during the $S$ phase of the cell cycle (25). Our results demonstrate a radiosensitizing effect of NAM $(0.5 \mathrm{~Gy})$ in cells deficient of BRCA1 (MDA-MB-436) and p53 (MDA-MB-231), compared to MCF-7 cells. In agreement with our results, it was previously reported that MCF-7 cells exhibit resistance to cell death induced by ionizing radiation caused by lack of caspase- 3 activity (26).

The results of the siRNA demonstrate that depletion of PARP1 has only a modest effect on reducing cell viability. However, it is known that NAM exerts a number of biological actions including inhibition of SIRT1 (silent mating-type information regulation 2 , homolog 1 ), which is a $\mathrm{NAD}^{+}$-dependent deacetylase that regulates the processes of stress response and cell survival (23). Studies have shown that SIRT1 inhibition by NAM decreases the viability of MCF-7 cells by inducing apoptosis through the activation of caspases (27) as well as growth inhibition and chemosensitization to gemcitabine in pancreatic cells (28).

Our findings and those of other studies on the antitumor effects of NAM in a number of cancer models suggest that this drug that can be clinically tested as a repositioned cancer drug. A major drawback for its potential application is that the antitumor effects of NAM require drug concentrations in millimolar ranges $(>10 \mathrm{mM})$ when used as single agent. However, when used for radiosensitization or in combination with cytotoxic drugs, the effects are seen at lower molar concentrations. Pharmacokinetic studies in cancer patients receiving oral high-dose NAM show that at doses of $6 \mathrm{~g}$ daily, peak plasma concentrations can be as high as $>200 \mu \mathrm{g} / \mathrm{ml}$, which corre- 


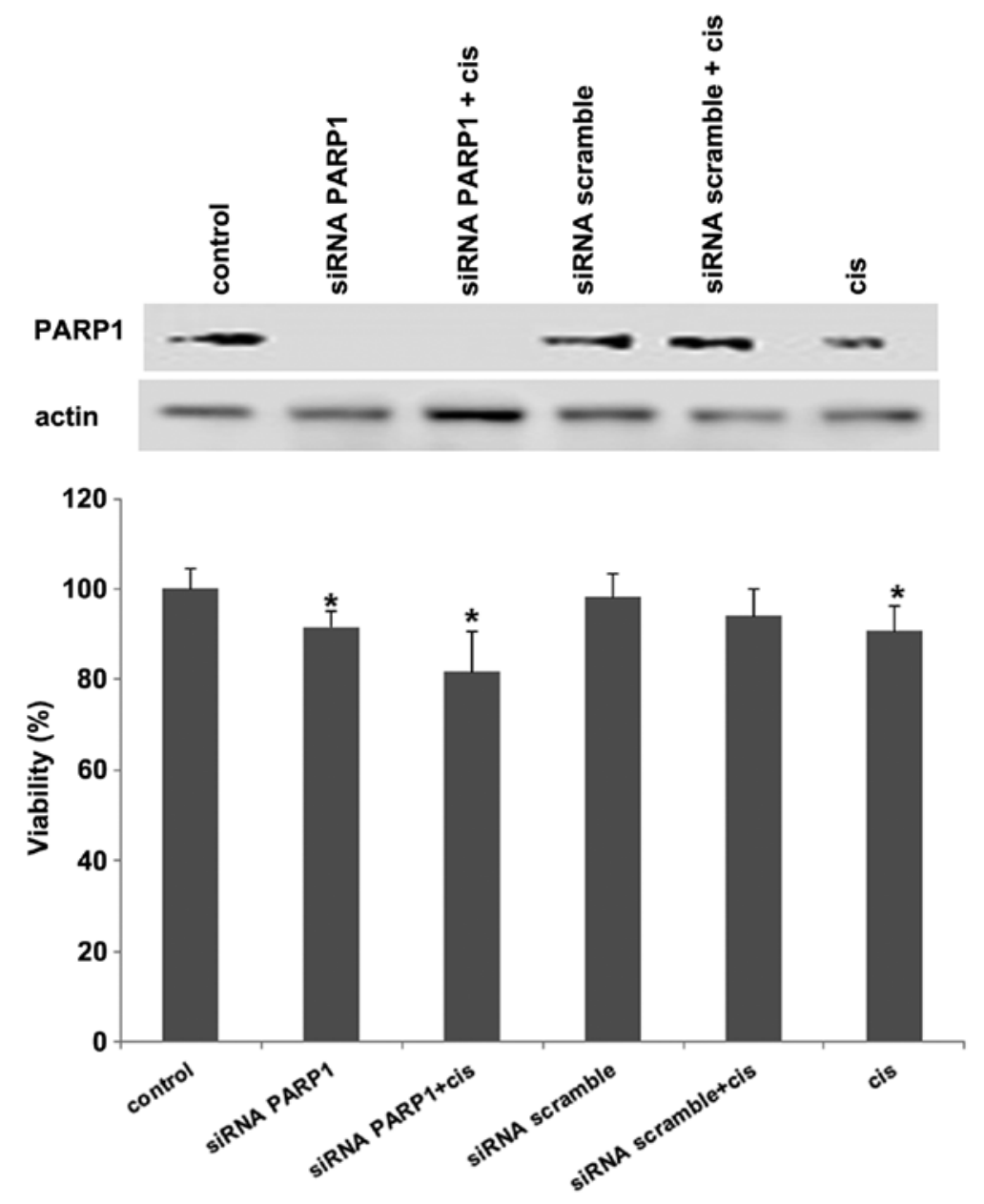

Figure 5. Growth inhibition by knockdown of PARP1 by siRNA. MDA-MB-436 cells were subjected to PARP1 knockdown by siRNA for $24 \mathrm{~h}$ and then treated with cisplatin for $24 \mathrm{~h}$. PARP1 protein expression and cell viability were assessed $24 \mathrm{~h}$ later. Scramble siRNA was used as a negative control. "Statistically significant differences in cell growth inhibition as compared to the control $(\mathrm{p}<0.01)$.
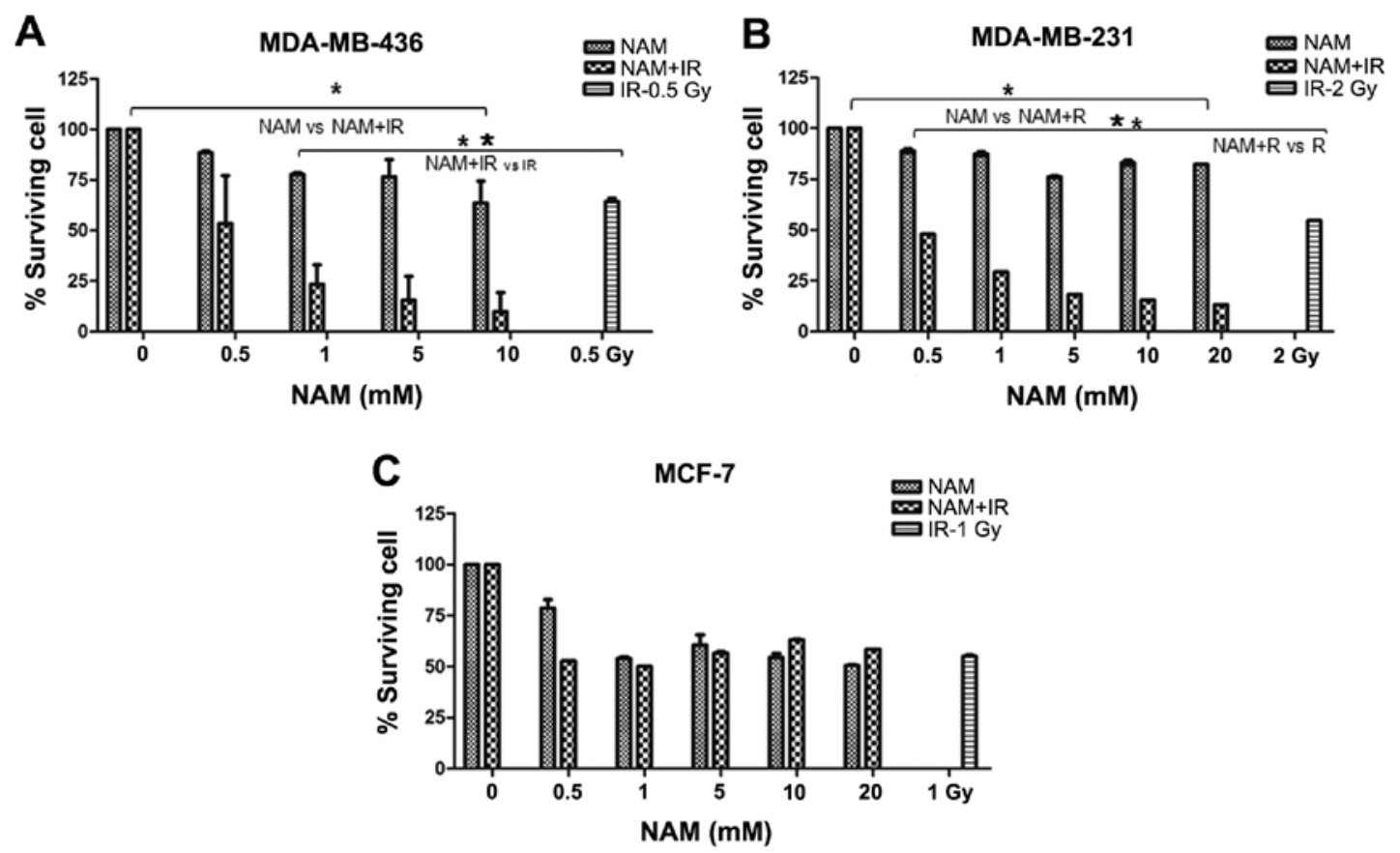

Figure 6. Radiosensitization by nicotinamide. (A) MDA-MB-436, (B) MDA-MB-231 and (C) MCF-7 cells were exposed to different concentrations of NAM for $72 \mathrm{~h}$ and IR. The IR dose varied depending on the cell line. Averages and SD from at least three experiments are shown. "Statistically significant as compared to NAM vs. NAM+IR ( $<<0.001) ;{ }^{* *}$ Statistically significant as compared to IR vs NAM+IR $(\mathrm{P}<0.001)$. 
sponds to molar concentrations $>2 \mathrm{mM}$. No clinical significant toxicity other than easily controlled nausea and vomiting were observed (29-31). In summary, further investigation on NAM is required to evaluate its activity in other tumor models as well as to demonstrate whether it increases the efficacy of combined chemoradiation.

\section{Acknowledgements}

The authors would like to thank Dr Patricia García López for valuable comments concerning this study as well as M.C. Roberto Lazzarini for technical assistance. This study was supported by CONACYT Mexico grant (203457).

\section{References}

1. Davar D, Beumer JH, Hamieh L and Tawbi H: Role of PARP inhibitors in cancer biology and therapy. Curr Med Chem 19: 3907-3921, 2012

2. Hirai T, Shirai H, Fujimori H, Okayasu R, Sasai K and Masutani M: Radiosensitization effect of poly(ADP-ribose) polymerase inhibition in cells exposed to low and high liner energy transfer radiation. Cancer Sci 103: 1045-1050, 2012.

3. Michels J, Vitale I, Senovilla L, et al: Synergistic interaction between cisplatin and PARP inhibitors in non-small cell lung cancer. Cell Cycle 12: 877-883, 2013.

4. De Soto JA, Wang X, Tominaga Y, et al: The inhibition and treatment of breast cancer with poly (ADP-ribose) polymerase (PARP-1) inhibitors. Int J Biol Sci 2: 179-185, 2006.

5. Bryant HE, Schultz N, Thomas HD, et al: Specific killing of BRCA2-deficient tumours with inhibitors of poly(ADP-ribose) polymerase. Nature 434: 913-917, 2005.

6. Farmer H, McCabe N, Lord CJ, et al: Targeting the DNA repair defect in BRCA mutant cells as a therapeutic strategy. Nature 434: 917-921, 2005.

7. Murphy CG and Moynahan ME: BRCA gene structure and function in tumor suppression: a repair-centric perspective. Cancer J 16: 39-47, 2010.

8. Hilton JF, Hadfield MJ, Tran MT and Shapiro GI: Poly(ADPribose) polymerase inhibitors as cancer therapy. Front Biosci 1 1392-1406, 2013.

9. Gupta SC, Sung B, Prasad S, Webb LJ and Aggarwal BB: Cancer drug discovery by repurposing: teaching new tricks to old dogs. Trends Pharmacol Sci 34: 508-157, 2013.

10. Dueñas-González A, García-López P, Herrera LA, MedinaFranco JL, González-Fierro A and Candelaria M: The prince and the pauper. A tale of anticancer targeted agents. Mol Cancer 7: 82,2008

11. Surjana D, Halliday GM and Damian DL: Role of nicotinamide in DNA damage, mutagenesis, and DNA repair. J Nucleic Acids 2010 pii:157591, 2010

12. Knip M, Douek IF, Moore WP, et al: European Nicotinamide Diabetes Intervention Trial Group Safety of high-dose nicotinamide: a review. Diabetologia 43: 1337-1345, 2000.

13. Virag L and Szabo C: The therapeutic potential of poly(ADPribose) polymerase inhibitors. Pharmacol Rev 54: 375-342, 2002.

14. Chen G and Zeller WJ: Reversal of acquired cisplatin resistance by nicotinamide in vitro and in vivo. Cancer Chemother Pharmacol 3: $157-162,1993$
15. Kaanders JH, Bussink $\mathbf{J}$ and Van der Kogel AJ: ARCON: a novel biology-based approach in radiotherapy. Lancet Oncol 3: 728-737, 2002.

16. Janssens GO, Rademakers SE, Terhaard CH, et al: Accelerated radiotherapy with carbogen and nicotinamide for laryngeal cancer: results of a phase III randomized trial. J Clin Oncol 30: 1777-1783, 2012.

17. Bernier J, Denekamp J, Rojas A, et al: ARCON: accelerated radiotherapy with carbogen and nicotinamide in head and neck squamous cell carcinomas. The experience of the Co-operative group of radiotherapy of the european organization for research and treatment of cancer (EORTC). Radiother Oncol 55: 111-119, 2000.

18. Bernier J, Denekamp J, Rojas A, et al: ARCON: accelerated radiotherapy with carbogen and nicotinamide in non-small cell lung cancer: a phase I/II study by the EORTC. Radiother Oncol 52: 149-56, 1999.

19. Handfield-Jones S, Jones SK and Peachey RD: Nicotinamide treatment in diabetes. Br J Dermatol 116: 277, 1987.

20. Niren NM: Pharmacologic doses of nicotinamide in the treatment of inflammatory skin conditions: a review. Cutis 77 (1 Suppl): 11-16, 2006.

21. Kolb H and Burkart V: Nicotinamide in type 1 diabetes. Mechanism of action revisited. Diabetes Care 22 (Suppl 2): B16-B20, 1999.

22. Vallely JF, Lovegrove TD and Hobbs GE: Nicotinic acid and nicotinamide in the treatment of chronic schizophrenia. Can Psychiatr Assoc J 16: 433-435, 1971.

23. Jung-Hynes B, Nihal, M, Zhong W and Ahmad N: Role of sirtuin histone deacetylase SIRT1 in prostate cancer. A target for prostate cancer management via its inhibition? J Biol Chem 284: 3823-3832, 2009.

24. Audrito V, Vaisitti T, Rossi D, et al: Nicotinamide blocks proliferation and induces apoptosis of chronic lymphocytic leukemia cells through activation of the p53/miR-34a/SIRT1 tumor suppressor network. Cancer Res 71: 4473-4483, 2011.

25. Evers B, Drost R, Schut E, et al: Selective inhibition of BRCA2deficient mammary tumor cell growth by AZD2281 and cisplatin. Clin Cancer Res 14: 3916-3925, 2008.

26. Löser DA, Shibata A, Shibata AK, Woodbine LJ, Jeggo PA and Chalmers AJ: Sensitization to radiation and alkylating agents by inhibitors of poly(ADP-ribose) polymerase is enhanced in cells deficient in DNA double-strand break repair. Mol Cancer Ther 9: 1775-1787, 2010.

27. Wang T, Cui H, Ma N and Jiang Y: Nicotinamide-mediated inhibition of SIRT1 deacetylase is associated with the viability of cancer cells exposed to antitumor agents and apoptosis. Oncol Lett 6: 600-604, 2013

28. Gong DJ, Zhang JM, Yu M, Zhuang B and Guo QQ: Inhibition of SIRT1 combined with gemcitabine therapy for pancreatic carcinoma. Clin Interv Aging 8: 889-897, 2013.

29. Dragovic J, Kim SH, Brown SL and Kim JH: Nicotinamide pharmacokinetics in patients. Radiother Oncol 36: 225-228, 1995.

30. Bernier J, Stratford MR, Denekamp J, et al: Pharmacokinetics of nicotinamide in cancer patients treated with accelerated radiotherapy: the experience of the Co-operative Group of Radiotherapy of the European Organization for Research and Treatment of Cancer. Radiother Oncol 48, 123-133, 1998.

31. Horsman MR, Hoyer M, Honess DJ, Dennis IF and Overgaard J: Nicotinamide pharmacokinetics in humans and mice: a comparative assessment and the implications for radiotherapy. Radiother Oncol 27: 131-139, 1993. 